\title{
Un círculo virtuoso, el espíritu del Vaticano ॥ se encuentra con el espíritu del 68
}

\author{
A Virtuous Cycle: The Spirit of Vatican II Meets the Spirit of '68
}

Gerd-Rainer HORN

Centre d'Histoire de Sciences Po, Paris

gerdrainer.horn@sciencespo.fr

\begin{abstract}
The article wishes to pay attention to two related, but analytically separate, features of the history of the Long Sixties in Western Europe. On the one hand, it focuses on a significant wave of progressive Catholicism which emerged in the wake of Vatican II. Often just one or two years later, secular social movements likewise began to make their mark on European society in the proverbial Long Sixties culminating in the events of 1968. By virtue of the fact that Catholic activism often predate secular activism by a few years, Catholic activists often played disproportionate roles in the atmosphere of heightened social movement activity in many European societies, a moment sometimes referred to as the «spirit of 1968 .
\end{abstract}

Keywords: Vatican II; 1968; student movements; workers' movement; radical priests; transnational history.
Resumen: El artículo presta atención a dos rasgos distintivos relacionados, pero analíticamente separados, de la historia de los años sesenta en Europa occidental. Por un lado, se centra en la significativa oleada de catolicismo progresivo que surgió a raíz del Vaticano II. Uno o dos años más tarde, los movimientos sociales seculares también comenzaron a dejar su huella en la sociedad europea en los proverbiales Long Sixties que culminaron en los acontecimientos de 1968. En virtud del hecho de que el activismo católico es anterior en el tiempo al activismo secular, los activistas católicos a menudo jugaron un papel desproporcionado en la atmósfera de la actividad del movimiento social en muchas sociedades europeas, momento que habitualmente es conocido como el «espíritu del 68».

Palabras clave: Concilio Vaticano II; 1968; movimiento estudiantil; movimiento obrero; sacerdotes radicales; historia transnacional.

\section{EL MOMENTO DE 1968}

Mayo de 1968 constituyó uno de esos raros «momentos de crisis y oportunidad» o «momento transnacional de cambio» en la historia, en que, de repente, el tiempo parece acelerarse, cuando la sabidurías recibidas y las creencias políticas que se creen estables y duraderas, surgen como de la nada, cautivando la imaginación de innumerables individuos, viejos o jóvenes, y dando entrada a esperanzas calladas y anhelos utópicos ${ }^{1}$.

1 He coeditado un pequeño volumen donde nos esforzamos por describir y analizar esos «momentos de crisis y oportunidad» en Europa de la década de los 40 a la de los 80, Gerd-Rainer HoRN y Padraic KENNEY (eds.), Transnational Moments of Change. Europe, 1945, 1968, 1989, Rowman \& Littlefield, Lanham, 2003. 
El año 1968 fue uno de esos momentos de cambio, real e imaginario, como lo fueron los periodos finales y sucesivos a cada una de las dos guerras mundiales: 1917-1923 y 1943-1948.

Con frecuencia, ese punto de inflexión en la historia presenta un límite espacial como, por ejemplo, 1989, que afectó «solamente» al Este de Europa, o 1848 que «sólo» dejó huellas profundas en gran parte de Europa dejando al margen a Gran Bretaña, la Rusia zarista y gran parte del resto del mundo ${ }^{2}$. Las secuelas de la Primera y la Segunda Guerra Mundial tuvieron efectos más globales, especialmente la última de ellas que dejó pocos rincones del planeta sin tocar. El año 1968 destaca como otro momento de disturbios mundiales, más notable aún por su carácter global durante una coyuntura sino de prosperidad si ciertamente de paz duradera. Los momentos de 1848, 1917 a 1923, 1943 a 1948 y 1989, por contraste, tuvieron lugar en tiempos de crisis política y/o económica. Otra peculiaridad del momento de 1968 fue el inusual y destacado papel de la oposición de inspiración religiosa al reinante status quo -al menos en occidente y en el Sur de Europa donde corrientes católicas y protestantes se disputaron la atención de ese «mundo nuevo»-, a menudo codo a codo con activistas seculares, en su intento por prevalecer.

En las páginas que siguen, deseo concentrarme en el papel de los movimientos católicos en la Europa de 1968, porque fue en la católica Europa dónde esta búsqueda de la liberación de las restricciones terrenas por un significado número de activistas fue más asombrosa. Hasta ahora, el mundo católico era poco conocido como fuerza poderosa capaz de un cambio progresista, cambio que ahora era percibido por activistas católicos cada vez más en la línea del progreso social de sus compañeros de armas no creyentes. En el paso del siglo diecinueve al veinte, la aparición de «sacerdotes democráticos» o de clero abiertamente comprometido del lado de las clases trabajadoras pobres urbanas -en muchos estados europeos importantes que experimentaban a la vez un proceso de industrialización, cambios políticos y culturales-, empezó a hacer oír su voz. En los últimos años de la Segunda Guerra Mundial e inmediatamente después, los movimientos sociales católicos progresistas -normalmente encabezados por personalidades e individuos eminentes pero aislados, cómo había sido el caso en la pionera etapa de los «abbés démocrates»-, empezaron a ver la luz del día, convirtiéndose en un fenómeno casi continental durante la ocupación nazi del oeste y del sur de Europa. $\mathrm{He}$

2 Téngase en cuenta, sin embargo, el importante impacto real de 1848 en las américas, como queda demostrado en Guy THOMSON (ed.), The European Revolutions of 1848 and the Americas, Institute of Latin Amerian Studies, London, 2002. 
bautizado este fenómeno como la primera ola de catolicismo de izquierdas ${ }^{3}$. Sin embargo, en el contexto de la guerra fría, esas notas de catolicismo progresista fueron rápidamente marginalizadas. En el curso de los años 60, y particularmente en su segunda mitad, surgió una segunda ola de catolicismo de izquierdas que superó rápidamente en profundidad social y dimensión geográfica a las primeras voces que, en las circunstancias de la ocupación nazi y la resistencia antifascista, se habían convertido en sus involuntarias pioneras. Esta segunda ola de católicos progresistas es la que constituye el núcleo de este artículo.

En particular deseo llevar a cabo dos tareas. Analizar y describir algunas de las diferentes maneras en que los activistas de la segunda ola de catolicismo de izquierdas dejaron una huella duradera en las comunidades católicas y, más importante aún, en la sociedad en general. Al mismo tiempo, mostrar las razones de la desproporcionada presencia y relevancia de los activistas católicos en los movimientos sociales asociados al 1968. Es evidente, más allá de toda duda, que el papel católico en la fase ascendente de las contestaciones sociales y culturales de los proverbiales «Long Sixties», es desproporcionada respecto a la presencia numérica de católicos en los respectivos contextos nacionales. Aunque este fenómeno no se limita a Europa, voy a circunscribir mi análisis al occidente y a la mitad meridional de este continente, que también fue testigo de algunas de las convulsiones sociales más turbulentas e internacionalmente reconocidas de $1968^{4}$. Sin embargo, para centrar mi atención en la fase álgida del activismo católico radical en la estela del Vaticano II, me abstendré de analizar la postrera desaparición de la segunda ola de catolicismo de izquierdas que tuvo lugar en el curso de los años 70, ya que esa tarea excede los límites de espacio otorgados para esta contribución a la historia del catolicismo en los «Long Sixties» ${ }^{5}$.

3 Véase, Gerd-Rainer HoRn, Western European Liberation Theology, 1924-1959. The First Wave, Oxford University Press, Oxford, 2008.

4 El análisis de las siguientes páginas se encuentra en dos monografías que publiqué en estos últimos años: Gerd-Rainer HORN, The Spirit of '68. Rebellion in Western Europe and North America, 1956-1976, Oxford University Press, Oxford, 2007; e ID., The Spirit of Vatican II. Western European Progressive Catholicism in the Long Sixties, Oxford University Press, Oxford, 2015. Fue durante la investigación y la escritura de The Spirit of ' 68 donde me di cuenta de la importancia de las corrientes católicas en el hacerse y el configurarse del 68. De esta manera, dejé a un lado las contribuciones específicamente católicas, en las conflagraciones globales de ese período, en la redacción del primero de los volúmenes antes mencionados, y decidí dedicar una monografía aparte a la experiencia católica del 1968. ¡El espíritu del Vaticano II debería verse mejor como acompañante del espíritu del 68, y viceversa!

5 Los lectores interesados en la historia de la religión en Europa occidental, en general, iy no solo del catolicismo progresista! -en los largos sesenta- pueden acudir a la obra magistral de Hugh MCLEOD, The Religious Crisis of the 1960s, Oxford University Press, Oxford, 2011. 


\section{MaRio SAVIO y RUdi DutSCHKE}

La mayoría de los observadores que tratan de esclarecer los largos años sesenta resaltan la gradual aparición, en vísperas del 68, de un nuevo fenómeno en la política de izquierdas: el ascenso de una nueva izquierda que actuaba transnacionalmente. La mayoría de los historiadores de la nueva izquierda internacional tienden a ver a la nueva izquierda como un desafío totalmente o en parte secular respecto a lo se empezaba a denominar como la vieja izquierda (uso el término secular en el sentido de «sin motivación religiosa»). Al igual que la vieja izquierda -por ejemplo, la democracia social y el comunismo- era habitualmente vista como un fenómeno con contados y valiosos enlaces con el mundo religioso, la nueva izquierda era considerada como un producto de los debates ideológicos que no tenían nada que ver con cuestiones religiosas. Pero, ¿es esto cierto? Demos un vistazo a algunos de los primeros y conspicuos exponentes del fuerte crecimiento de la nueva izquierda internacional. ${ }^{6}$

Dos de los movimientos de nueva izquierda por excelencia en los prolegómenos de 1968 son conocidos por el mismo acrónimo debido a una casualidad lingüística: SDS (Students for a Democratic Society y el Sozialistischer Deutscher Studentenbund). El grupo de estudiantes de Estados Unidos por una sociedad democrática nació en 1960 y se desarrolló en paralelo a la radicalización de los campus de las universidades norteamericanas. El primer movimiento emblemático en esta oleada de movimientos sociales afincados en los campus universitarios, fue el llamado Berkeley Free Speech Movement, que surgió en el inicio del año académico de 1964-1965 en el campus de la Universidad de California en Berkeley. Este movimiento rápidamente polarizó el campus de Berkeley sirviendo de inspiración a otros movimientos similares en otras partes de Nortea-

6 Aún hoy en día y con diferencia, la presentación más completa y perspicaz de la Nueva Izquierda desde una perspectiva comparativa y transnacional es la de Massimo TEODORI, Storia delle nuove sinistre in Europa, 1956-1976, Il Mulino, Bologna, 1976. El estudio clásico de la más importante de todas las organizaciones radicales estudiantiles de EEUU, la Students for a Democratic Society (SDS), sigue siendo Kirkpatrick SALE, SDS, Random, New York, 1973. Tres monografías más recientes prestan una especial atención a las contribuciones religiosas (a menudo dejadas de lado) al SDS y a movimientos similares: Douglas C. RossinOw, The Politics of Authenticity. Liberalism, Christianity and the New Left in America, Columbia University Press, New York, 1998; James J. FARrell, The Spirit of the Sixties. The Making of Postwar Radicalism, Routledge, New York, 1997; y Sara Evans, Fourneys That Opened Up the World: Women, Student Christian Movements, and Social fustice, 1955-1975, Rutgers University Press, New Brunswick, 2003. El clásico estudio sobre el Berkeley Free Speech Movement sigue siendo Hal DraPER, Berkeley. The New Student Revolt, Grove Press, New York, 1965. 
mérica. Pero ¿quién era la principal figura de esta empresa pionera en el otoño de 1964 ?

Mario Savio era la figura indiscutible del movimiento de libertad de expresión de Berkeley y así es como describe su propia formación en un discurso a una audiencia netamente laica:

Crecí como católico. Era monaguillo e iba a ser sacerdote. Obviamente, el hijo mayor de una familia católica italiana estaba destinado a ser sacerdote, si alguien tendría que serlo, y yo iba a ser esa persona. (...) Me sumergí en la teología de la liberación. Leí cosas que probablemente la mayoría de la gente en esta sala no ha leído. Leí a Jacques Maritain a Emmanuel Mounier, cosas publicadas en el ambiente del Catholic Worker; estaba muy comprometido con este tipo de pensamiento ${ }^{7}$.

No deseaba hacer carrera. Era de los que me tomaba las cosas buenas o malas con una excepcional seriedad. Tenía dos tías que fueron monjas. Podría haber sido sacerdote. Y, de repente, aparece el movimiento por los derechos civiles. Y desde entonces me he alejado de la Iglesia, y veo el movimiento de los derechos civiles en términos religiosos. En el movimiento por los derechos civiles estaban todos esos ministros; estaba plagado de ministros. Y esto para mí fue un ejemplo de cómo Dios obra en el mundo ${ }^{8}$.

Así que cuando Mario Savio se quitó los zapatos antes de saltar al techo del coche de policía en el campus de Berkeley para llamar a la huelga, su activismo estaba guiado en gran medida por una indignación de trasfondo religioso a consecuencia del estado del mundo. Junto con otros estudiantes, acababa de regresar de su veraneo en el profundo sur americano donde estudiantes blancos del norte habían ayudado a estudiantes negros en una campaña que ha entrado en los anales de la historia bajo el nombre de «el verano de la libertad»?.

El movimiento por los derechos civiles americano, no era solo el típico movimiento social americano que enseñó a muchos americanos blancos las políticas de protesta, sino que era también, como subraya Mario Savio, un movimiento liderado y llevado a cabo, en gran medida, por motivaciones religiosas. Coincidentemente, Martin Luther King Jr., la figura emblemática del movimiento por los

7 Mario SAVIO, Thirty Years Later. Reflections on the FSM, en Robert COHEN y Reginald E. ZELNIK (eds.), The Free Speech Movement. Reflections on Berkeley in the 1960s, University of California Press, Berkeley, 2002, p. 59.

8 Ibid., p. 61.

9 Doug MCADAM, Freedom Summer, Oxford University Press, New York, 1988, es la lectura esencial sobre este tema. 
derechos civiles, no solo era pastor, sino que había escrito su tesis doctoral sobre dos teólogos protestantes, uno de ellos el alemán (o alemán-americano, si se prefiere) Paul Tillich ${ }^{10}$. No es necesario insistir en el hecho de que el protestantismo tuvo un papel más prominente en los años sesenta en suelo americano entre los ambientes cristianos que el catolicismo, debido a su mayor presencia numérica. Pero los nombres de Daniel y Philip Berrigan están indivisiblemente unidos a los momentos cruciales de la oposición religiosa a la Guerra del Vietnam; los Berrigan eran sacerdotes católicos, dos entre muchos, que dejaron una huella duradera en la cultura de protesta americana de los largos sesenta ${ }^{11}$.

Paul Tillich, uno de los dos pensadores estudiados en la tesis doctoral de Martin Luther King Jr., era, igualmente, uno de los héroes de otro de los integrantes del salón de la fama de los estudiantes radicales de la nueva izquierda de los años 1960. El carismático líder de la SDS (Sozialistischer Deutscher Studentenbund) Asociación de Estudiantes socialistas alemanes de Alemania Occidental, Rudi Dutschke. Dutschke llegó a ser la figura más popular de los estudiantes de izquierda de la Alemania occidental, inspirando a toda una generación de estudiantes universitarios para que tomaran las calles ${ }^{12}$. Pocos de sus seguidores sabían probablemente que Rudi Dutschke era un creyente de toda la vida. Su compañero de fatigas vital, a propósito, era un estudiante de teología americano, Gretchen Klotz. He aquí una cita de una entrada de su diario en 1963, cuando Dutschke estaba ya embarcado en el viaje intelectual que le llevaría a mezclar y a fundir creativamente lo que él consideraba lo mejor de la tradición Situacionista y lo mejor de la nueva izquierda, y todo ello inspirado por sus convicciones religiosas.

10 Existe una controversia pública sobre las acusaciones de plagio en la tesis doctoral de Martin Luther King presentada en la Universidad de Boston en 1955. Para una interpretación autorizada sobre este asunto, véase, Martin Luther King Jr. Papers Project, The Student Papers of Martin Luther King 7r:: A Summary Statement on Research, en The fournal of American History, 78/1 (1991), pp. 23-31. Esta controversia, sin embargo, no debe restar valor a la verdadera inspiración que Martin Luther King Jr. encontró en el personalismo europeo para su propia carrera religiosa y activista.

11 Murray Polner y Jim O'GRADY, Disarmed and Dangerous. The Radical Lives and Times of Daniel and Philip Berrigan. Brothers in Religious Faith and Disobedience, Basic Books, New York, 1997.

12 Tres monografías proporcionan distintos acercamientos a la personalidad y a la actividad de uno de los líderes estudiantiles por excelencia del 68: Ulrich CHAUssy, Die drei Leben des Rudi Dutschke. Eine Biographie, Luchterhand, Darmstadt, 1983; Gretchen DuTsCHKE, Rudi Dutschke. Wir hatten ein barbarisches, schönes Leben. Eine Biographie, Kiepenheuer und Witsch, Cologne, 1996; y Michaela KARL, Rudi Dutschke. Revolutionär obne Revolution, Neue Kritik, Frankfurt am Main, 2003. 
«Jesús ha resucitado; la alegría y el agradecimiento son nuestros compañeros en este día; la revolución, la revolución decisiva de la historia mundial ha ocurrido, la revolución del mundo por medio del amor que todo lo conquista. Si los seres humanos hubieran aceptado totalmente este amor como su luz guiadora, la realidad del aquí y ahora, la lógica de la locura, no sobreviviría por mucho más tiempo» ${ }^{13}$.

Hasta ahora me he referido de igual modo tanto a la dimensión protestante como a la católica del radicalismo religioso de los 60. Lo he hecho de esta manera para subrayar que no hay nada mágico en el radicalismo católico de los largos sesenta. Otras denominaciones religiosas fueron de igual modo atrapadas por el espíritu de ese tiempo. En la vida real, algunas veces es más complicado desenredar las específicas contribuciones de cada una de las ramas de las variadas religiones del mundo. Con todo, en lo que queda de artículo, me dirigiré exclusivamente a los eventos que afectaron o fueron generados en el mundo católico.

\section{ESTUDIANTES CATÓLICOS EN ACCIÓN}

Holanda, por varios motivos, fue uno de los puntos calientes de la política y la cultura de la disconformidad en los largos sesenta y el Rudi Dutschke holandés era un tal Ton Regtien. En Holanda era el equivalente exacto de Mario Savio en Berkeley, y por lo tanto en los Estados Unidos, o de Rudi Dutschke en Berlín occidental y por ende en Alemania occidental. El look de Regtien se parecía al de Dutschke -rasgos oscuros, cabellos largos- lo que sin duda contribuyó a su popularidad. Pero su nombre delataba su procedencia familiar: Ton por Antonio, y su segundo nombre era Aegidius. Antonius Aegidius Regtien era el cuarto de ocho hermanos nacidos en una familia católica de clase media trabajadora en Ámsterdam. A la edad de dieciséis años entró en el seminario de Venlo, dejándolo dos años más tarde, y al acabar la escuela pasó por varias universidades, en las que contribuyó significativamente en la construcción de potentes asociaciones de estudiantes de nueva izquierda, las Studentenvakbeweging (SVB), de las cuales hablaremos más adelante. Hacia 1966, el exseminarista Ton Regtien contrabandeaba con los soldados del ejército de Estados Unidos para encontrar un refugio seguro en Francia y Suecia, mientras trataba de subvertir las sociedades holandesas y europeas participando frecuentemente en reuniones internacionales en las

13 Rudi Dutschke, feder hat sein Leben ganz zu leben. Die Tagebücher 1963-1979, вTВ, Cologne, 2005, p. 17. 
que los estudiantes radicales planeaban cambiar el mundo. Cuando Ton Regtien murió a finales de los 80, dos conocidos sacerdotes holandeses activistas ocupaban los asientos del primer coche que seguía al coche fúnebre ${ }^{14}$.

El equivalente flamenco de Rudi Dutschke y Ton Regtien era Paul Goossens. Paul Goossens se convirtió en la quintaesencia de los portavoces de los estudiantes radicales flamencos a partir de 1966. Al igual que Ton Regtien, Paul Goossens había elegido entrar en el seminario. Y cuando, más tarde, fue catapultado a la primera fila del movimiento de estudiantes belgas lo hizo como miembro de la Liga Universitaria católica flamenca, la organización católica señera de los estudiantes universitarios ${ }^{15}$.

Uno de los más célebres nombres que surgieron del vivero de los estudiantes italianos en los largos años sesenta fue Mario Capanna. Mario Capanna era estudiante en la Universidad Católica más grande de Italia, La Cattolica, la Universidad del Sagrado Corazón en Milán. En sus memorias, Capanna rememora el estresante programa de estudio, incluida la constante presión por sobresalir en los exámenes. Cualquier fallo en la obtención de las máximas calificaciones causaba la pérdida de las becas conduciendo a la terminación de los estudios universitarios en el caso de aquellos que no tenían la fortuna suficiente de haber nacido en los niveles más altos de la sociedad italiana. «Estudiábamos día y noche. Pero no solo para preparar los exámenes». Capanna y su círculo inmediato de amigos, tenían un interés poco común en aquellos tiempos en La Cattolica por «Marx y otros autores marxistas», pero tales frutos prohibidos no constituyeron de ninguna manera el único o el principal objeto de sus búsquedas extracurriculares: «Nosotros leíamos teólogos que estaban entonces considerados como innovadores, tales como Karl Rahner, Edward Schillebeeckx, Hans Urs von Balthasar. Sobre los cuales teníamos frecuentes discusiones que duraban hasta altas horas de la madrugada ${ }^{16}$.

La centralidad de esos pensadores católicos (y la relativa irrelevancia de Karl Marx) aparecen en innumerables artículos en La Cattolica en 1967 y 1968. Entre las autoridades citadas con más frecuencia en los inicios del activismo estudiantil en La Cattolica no hay autores marxistas sino «san Pablo y san Agustín, Juan XXIII y el Concilio Vaticano II; y la canción de tuna más popular del movimiento era el

14 Niek Pas, Regtien, Antonius Aegidius (1938-1989), en Biografisch Woordenboek van Nederland. URL:http:// resources.huygens.knaw.nl/bwn1880-2000/lemmata/bwn5/regtien [19-03-2015]; conversación telefónica de Gerd-Rainer Horn con Jan Ruijter, 11 de diciembre del 2013.

15 Paul Goossens, URL:https://nl.wikipedia.org/wiki/Paul_Goossens.

16 Mario CaPanNa, Formidabili quegli anni, Rizzoli, Milano, 1994, p. 18. 
Gloria, Gloria, Aleluya». Cuando los estudiantes y conferenciantes llegaban desde la universidad estatal de Milán, en el momento de la fase álgida del movimiento estudiantil en Milán y empezaban a cantar Bandiera rossa, los estudiantes de La Cattolica los mandaban callar con gritos y abucheos ${ }^{17}$. Durante una de las numerosas ocupaciones por parte de los incansables estudiantes de La Cattolica, las protestas duraron dos semanas desde finales de mayo hasta principios de junio.

En 1968, la misa era celebrada a diario en la capilla universitaria con presencia multitudinaria de estudiantes. «Además de los textos bíblicos, parte de los discursos de John F. Kennedy eran leídos en voz alta, y los espirituales negros sonaban junto con los cantos tradicionales. Con frecuencia, hacía el final, los celebrantes entonaban el We Shall Overcome (Venceremos), cuya melodía y texto era el que mejor expresaba la esperanza de los jóvenes activistas en el éxito de los ideales que los animaban ${ }^{18}$.

La lista de estudiantes radicales católicos podría extenderse indefinidamente. Pero ¿qué es lo que pasaba? ¿Por qué muchos de los portavoces de la izquierda estudiantil radical de 1960 estaban fuertemente influidos por motivaciones religiosas? ¿Qué explica está sorprendente regularidad con la que estudiantes católicos, aunque por supuesto no solo católicos, se convirtieron en los líderes por excelencia de la generación del 68?

\section{EL ESPÍRITU DEL VATICANO II}

En este contexto, es clave hacer referencia al Concilio ecuménico Vaticano II que tuvo lugar de otoño de 1962 a otoño de 1965. Después de décadas, si no de siglos, de pontificados conservadores (hubo excepciones, que en realidad confirman la regla), la inesperada y sin precedentes reforma de Juan XXIII abrió un período altamente inusual de profundas reformas en la Iglesia católica, probablemente la institución más antigua de occidente. Los esfuerzos en la dirección de lo que podría considerarse como un movimiento de democracia interna en la jerarquía institucional tuvieron su anuncio en el Vaticano II. Todavía más importante, a los fieles se les animó, de repente, a estudiar seriamente la sociedad y la

17 Roberto Beretta, Il lungo autunno. Controstoria del Sessantotto cattolico, Rizzoli, Milano, 1998, p. 28.

18 Entrevista al padre Nello Casalini en 1997, tomada por Beretta, Il lungo autumno, pp. 62-3. Junto con Mario Capanna, Nello Casalini fue un líder estudiantil clave en La Cattolica, el presidente de prácticamente todas las asambleas generales de estudiantes celebradas durante 1968 en el campus de Milán. Casalini entró en los franciscanos en 1973. 
realidad contemporáneas, en orden a determinar de qué manera los valores del Evangelio se habían materializado en el mundo de hoy. Más que depender de la doctrina tradicional o preestablecida para juzgar la realidad contemporánea, los creyentes católicos fueron alentados a confiar en los métodos de investigación que podríamos describir como sociológicos, históricos y antropológicos, para hacer los pertinentes juicios de valor sobre los fenómenos del mundo actual. Más aún, el compromiso a favor del oprimido y del pobre, que había sido predicado durante siglos en los sermones dominicales desde los púlpitos, fue tomado en serio por la jerarquía de la Iglesia.

$\ll$ El trabajo humano que se ejerce en la producción y en el comercio o en los servicios es muy superior a los restantes elementos de la vida económica, pues estos últimos no tienen otro papel que el de instrumentos», se lee en uno de los documentos del Vaticano II (GS 67). La misma «constitución pastoral sobre la Iglesia en el mundo moderno» (Gaudium et spes) recomendó «la activa participación de todos en la gestión de la empresa, según formas que habrá que determinar con acierto», lo que supone un membrete de aprobación por parte del Concilio de los varios modelos de co-determinación y participación de los trabajadores en el funcionamiento de sus empresas. Sorprendentemente, Gaudium et Spes fue un paso más allá: «Con todo, como en muchos casos no es a nivel de empresa, sino en niveles institucionales superiores, donde se toman las decisiones económicas y sociales de las que depende el porvenir de los trabajadores y de sus hijos, deben los trabajadores participar también en semejantes decisiones por sí mismos o por medio de representantes libremente elegidos» (GS 68).

Si los párrafos acerca de los derechos de los trabajadores eran ya llamas claras y oxigenantes para una profunda renovación del orden social reinante, Gaudium et Spes se reservó su más clara condenación para el status quo de las relaciones de clases en el tercer mundo:

En muchas regiones económicamente menos desarrolladas existen posesiones rurales extensas y aun extensísimas mediocremente cultivadas o reservadas sin cultivo para especular con ellas, mientras la mayor parte de la población carece de tierras o posee sólo parcelas irrisorias y el desarrollo de la producción agrícola presenta caracteres de urgencia. No raras veces los braceros o los arrendatarios de alguna parte de esas posesiones reciben un salario o beneficio indigno del hombre, carecen de alojamiento decente y son explotados por los intermediarios.

Y los padres conciliares, siguiendo una lógica clara, sugirieron que «las reformas eran necesarias», incluyendo la socialización de las tierras estatales: «más todavía, el reparto de las propiedades insuficientemente cultivadas a favor 
de quienes sean capaces de hacerlas valer» (GS 71), una medida verdaderamente revolucionaria de gran relevancia para la mayoría de los países en el mundo en los años sesenta, y una de las fuerzas motores detrás del origen de la teología de la liberación en los años siguientes. Es fácil ver como tales pasajes de Gaudium et Spes hincharon las velas de los activistas de la justicia social en todo el mundo, confirmando que una pequeña parte de ese ejército de activistas encontraron su inspiración en las enseñanzas católicas.

Rápidamente, el clásico mecanismo que frecuentemente opera entre los movimientos sociales se puso en marcha: un proceso de radicalización, el círculo virtuoso que crea mayores expectativas y pide demandas aún más atrevidas. De hecho, el «espíritu del Vaticano II», operando en múltiples niveles y en formas misteriosas, pronto comenzó a ser tema de múltiples interpretaciones. A medida que el ciclo de activismo propulsado por las inspiraciones cristianas se puso en marcha, el Vaticano II, muy pronto, fue usado como una metáfora para un gran número de posibles modelos de acción radicales. No era la precisa fraseología de las declaraciones del Concilio lo que contaba, sino las intenciones que podían estar escondidas detrás de esas palabras. Ciertamente, en los años que siguieron al Concilio, las manifestaciones concretas del espíritu del Vaticano II dejaron atrás, con frecuencia, a las sugerencias específicas que podrían ser legítimamente extraídas de las páginas de los documentos más relevantes. Como la teología posconciliar superó el significado textual de la mayoría de las declaraciones conciliares, los activistas católicos tomaron, de manera creativa, el asunto entre sus manos. Este fermento asombroso dentro de las comunidades de creyentes católicos es importante por el hecho de que, a mitad de los años 60, en muchos países de Europa Occidental un gran número de movimientos sociales -de los cuales los movimientos estudiantiles eran solo el componente más visible-, estaban animados en gran medida por católicos ${ }^{19}$.

Y entonces, uno de esos imprevistos e imprevisibles «signos de los tiempos» tuvo lugar: la chispa de la rebelión y de la contestación de repente comenzó a afectar, en gran medida, a la sociedad laica. Un proceso paralelo de radicalización gradual -en marcha desde por lo menos $1956 \mathrm{y}$ dando paso de manera lenta a

19 Un intento de esbozar la radicalización de ciertos sectores de la opinión católica progesista a raíz del Vaticano II, en mi breve artículo Gerd-Rainer HORN, Les chrétientés catholiques à l'épreuve des sixties et des seventies, en Yvon TranvOUEZ (ed.), La décomposition des chrétientés occidentales 19502010, Centre de Recherche Bretonne et Celtique, Brest, 2013, pp. 23-35. Una amplia muestra de detalles específicos de esta evolución puede encontrarse en todos los capítulos de mi obra The Spirit of Vatican II. 
una nueva izquierda poderosa e imaginativa (aludida al inicio de este artículo)-, se puso de manifiesto, dramáticamente, con acciones espectaculares en todos los países. Las motivaciones respectivas diferían según los casos. En los Estados Unidos la guerra de Vietnam era el catalizador, y el más temprano movimiento por los derechos civiles, en que el liderazgo religioso era clave, había enseñado a los americanos blancos las técnicas asociadas a las políticas de protesta. En España, las condiciones de una dictadura en medio del mundo libre, condicionaban la vitalidad y la volatilidad de las protestas culturales animadas por los católicos progresistas a partir de 1956, como veremos enseguida. En Bélgica, las condiciones peculiares de dominio económico y cultural francófono sobre una cada vez mayor e inquieta comunidad flamenca, con la jerarquía católica pendiente de esta relación desigual, llevó a una explosión de entusiasmo juvenil en mayo de 1966. El Mayo Francés de 1968 no fue de ninguna manera el primer gran conflicto social que marcó a la política europea (y al mundo) en los años 60, aunque sí se convirtió en el pistoletazo de salida que pudo escucharse en todo el mundo. Las corrientes religiosas y seculares radicales se habían embarcado en una carrera conjunta hacia la cumbre jaleándose mutuamente, codo con codo, creando una dinámica en apariencia imparable.

Lo que estoy tratando de sugerir es esto: la radicalización católica en el despertar del Vaticano II en muchos casos precedió a la radicalización de las comunidades seculares. Los Estados Unidos son, por supuesto, una importante excepción gracias al temprano desarrollo del movimiento por los derechos civiles, aunque aquí el componente religioso es presentado como un sumando. Los movimientos radicales de la nueva izquierda con frecuencia precedían el Concilio Vaticano II, pero en muchos contextos nacionales permanecieron apagados durante la primera parte de la década de los sesentas e incluso a lo largo del camino que llevó al 68. Pero ya antes de 1968, las comunidades católicas habían experimentado un latente pero importante proceso de radicalización a lo largo de numerosos años. En 1968, los activistas católicos del floreciente catolicismo de izquierdas ya eran experimentados veteranos de un gran número de importantes movimientos, así que para el tiempo en que la sociedad empezaba a agitarse, en o alrededor de 1968, el rol de los activistas católicos en los movimientos sociales de aquella época revestía una importancia desproporcionada comparada con su presencia numérica en el total de la sociedad. Los activistas católicos con frecuencia encarnaron el papel de pioneros y líderes a los ojos de sus admiradores laicos, con la correspondiente asunción de posiciones importantes en los movimientos sociales de su época. 


\section{EL PAPEL DE VANGUARDIA DE LAS UNIVERSIDADES CATÓLICAS}

Con anterioridad, he sugerido que las acciones llevadas a cabo por los más famosos líderes estudiantiles de la generación de 1968 sacaron a la luz un significativo número de católicos oficiales. ¿Eran personajes importantes, aunque en definitiva irrelevantes desde el punto de vista cuantitativo o, simplemente, productos aislados de la cultura de protesta católica? Un rápido vistazo al papel de las universidades católicas sugiere que tanto Paul Goossens, como Mario Capanna o Ton Regtien no eran solamente casos simbólicos, sino que representaban una tendencia más amplia. En Europa occidental, con una regularidad asombrosa, las universidades católicas estuvieron en primera línea y a la vanguardia del movimiento estudiantil de los largos sesenta.

Acabo de referir, hace poco, a los eventos de La Cattolica de Milán. Pero lo que no mencioné es que fue precisamente en La Cattolica donde los movimientos de estudiantes italianos tuvieron relevancia por primera vez. La ocupación del campus de La Cattolica, en octubre de 1967, fue la primera ocupación de un campus universitario en Italia que llamó la atención de todo el país. Y La Cattolica seguiría jugando un papel importante en la política estudiantil radical italiana en lo que quedaba de década ${ }^{20}$. La cuna de la protesta estudiantil italiana, de todas maneras, estaba al norte de Milán. Fue en la pequeña ciudad de Trento, en el lado occidental de las Dolomitas, dónde, en octubre de 1966, ocurrió la primera de todas las ocupaciones de los campus de Italia en los años 60. Esa primera ocupación no provocó ningún titular en la prensa, debido a que el campus era más bien pequeño. Pero dentro de los círculos estudiantiles se convirtió de inmediato en algo famoso e inspirador de las restantes luchas por los campus, entre ellos el de La Cattolica. El cuerpo de estudiantes en el Instituto de Sociología, como era llamado, y que era el precursor de lo que hoy conocemos como la Universidad de Trento, estaba

20 Dos artículos estimulantes sobre el laboratorio de experiencias del movimiento social en La Cattolica han sido escritos por un especialista británico en estudios italianos: Robert LUMLEY, States of Emergency: Cultures of Revolt in Italy from 1968 to 1978, Verso, London, 1990, pp. $77-$ 86, que proporciona un perspicaz y estimulador resumen de los parámetros de la vida estudiantil en La Cattolica en 1967-8; el mismo autor ha escrito Il Movimento Studentesco di Milano, en Aldo Agosti, Luisa Passerini y Nicola Tranfaglia (eds.), La cultura e i luoghi del '68, Franco Angeli, Milan, 1991, pp. 267-274, es también un recurso útil para comprender por qué La Cattolica se convirtió en el caldo de cultivo del radicalismo estudiantil católico desde muy temprano. 
casi exclusivamente compuesto de estudiantes católicos provenientes de toda Italia $^{21}$.

Antes mencioné a Paul Goossens como el Rudi Dutschke de la parte flamenca de Bélgica. La institución en la que estudiaba y a la que dio la vuelta era ni más ni menos que la Universidad Católica de Lovaina, la más antigua universidad católica más allá de los Alpes y la mayor universidad en tierra flamenca. De hecho, la primera universidad de Europa occidental que se convirtió en el centro de una polémica nacional en el curso de los años 60 no fue ni la Universidad de París ni la Libre de Berlín. La primera población universitaria testigo de carreras y luchas entre manifestantes y la policía fue la flamenca población de Lovaina. La muy católica universidad de Lovaina, fundada en 1425, tiene el honor de haber desatado la gran polémica que llevó a altercados callejeros y a la polarización de la opinión pública a lo largo y ancho del país ${ }^{22}$.

Por lo tanto, no nos sorprenderá que el campus donde Ton Regtien se ejercitó a mediados de los sesenta no fuera otro que el de la mayor universidad católica holandesa, la Universidad de Nimega. Aquí fue donde se creó el equivalente a la sociedad de estudiantes socialistas (SDS) de Alemania occidental y de los Estados Unidos, y desde donde se extendió al resto de Holanda: la Studentenvakbeweging (SVB), que significa literalmente «movimiento sindical estudiantil». Pero la chispa final que desató una reacción en cadena de protestas radicales en toda Holanda tuvo lugar en Tilburg, a ochenta quilómetros al sudoeste de Nimega, sugiriendo, una vez más, fuertes vínculos entre el asociacionismo católico y las revueltas en la sociedad. Porque Tilburg era la sede de otra institución católica de alta enseñanza, el Katholieke Hogeschool Tilburg (KHT), y este «colegio» se convirtió en la primera

21 El tratamiento más completo sobre el activismo radical católico en Trento es, ahora mismo, Alessandro CHINI, Il dissenso cattolico. Dal postconcilio al referendum sul divorzio in Italia e a Trento, Edizioni UCT, Trento, 2009, aunque otras publicaciones sobre el radicalismo de Trento incluyen también discusiones perspicaces sobre la contribución específicamente católica.

22 Una monografía bien informada y escrita sobre los problemas que rodearon la división de la Universidad Católica de Lovaina, con el problema subyacente detrás de la aparición temprana de un vibrante movimiento estudiantil radical en Flandes es la obra de Christian LAPORTE, L'affaire de Louvain: 1960-1968, De Boeck Université, Paris, 1999. Paul GoOsSENS, Leuven '68 of het geloof in de hemel, Roularta, Zellik, 1993, es el recuerdo de esa lucha por parte del principal portavoz del movimiento estudiantil de Lovaina. La autoridad indiscutible del movimiento estudiantil en Lovaina, sin embargo, es Louis Vos, un antiguo estudiante de Lovaina surgido en el auge de los altercados en las calles de esa ciudad, que ahora ha reunido su rica colección de artículos sobre este tema en Louis VOS, Idealisme en engagement. De roeping van de katholieke studerende jeugd in Vlaanderen (1920-1990), Acco, Leuven, 2011. Un documental estimulante e informativo sobre este conflicto por excelencia en los años sesenta belgas puede consultarse aquí: http://www.sonuma.com/archive/le-problème-de-louvain. 
universidad holandesa que estalló. Aun así, en 1963, el 83\% de todos los estudiantes del Colegio Católico de Tilburg acudían regularmente a la misa dominical.

La ocasión para que explotara una batalla abierta en Tilburg surgió en el contexto de un amplio debate que se llevaba a cabo en el campus sobre la democratización de la administración universitaria, en que los estudiantes pedían la co-determinación a todos los niveles. Al anochecer del 28 de abril de 1969, estudiantes organizados del Frente de Izquierda tomaron la sala de asambleas donde el Senado de la universidad había -a las 8 de la noche de ese día-, decidido rechazar firmemente las demandas de los estudiantes. A la mañana siguiente, la centralita telefónica de la Universidad fue asaltada por una multitud enfadada ${ }^{23}$.

Nos llevaría demasiado lejos tratar de describir toda la dinámica de la revuelta estudiantil holandesa. La cuestión principal es que todo empezó en una universidad católica, así como la radical SVB se había enraizado en el campus de la mayor universidad católica de Holanda, en Nimega. Nos podemos preguntar, entonces, qué papel jugó en el curso de los eventos sucedidos en Nimega, Tilburg, Lovaina y en otros lugares, el ambiente católico de estos activistas. Ton Regtien era sólo uno de los muchos activistas-observadores que llamó la atención sobre la vinculación entre catolicismo y activismo radical en los largos años 60, pero la prominencia de Regtien da un crédito particular a sus puntos de vista: «Justo en ese momento, las corrientes radicales que clamaban por una renovación se hicieron con los ambientes católicos». Eran los tiempos del Concilio Pastoral Holandés [un movimiento apoyado por la entera jerarquía católica holandesa que intentaba revolucionar la Iglesia Católica], y Nimega y Tilburg habían despertado de su estado de hibernación inducido por su incuestionable obediencia a las autoridades romanas. Allí se dio una recíproca influencia entre el no conformismo religioso y el político. Tanto la autoridad del papa como la del Partido Popular Católico (Katholieke Volks Partij) [el partido católico holandés por excelencia] se vieron atacados ${ }^{24}$. Desde este punto de vista, ¿tuvo el catolicismo un papel destacado como fuerza negativa contra la cual revelarse?

23 Sobre la historia del crucial SVB, véase Hugo KIJNE, Geschiedenis van de Nederlandse Studentenbeweging 1963-1973, SUA, Amsterdam, 1978, pp. 37-68; pero también Jacques JANSSENS y Paul Voestermans, Studenten in beweging. Politiek, universiteit en student, Katholiek Studiecentrum, Nijmegen, 1984, pp. 90-121. Sobre el papel de Tilburg en la genesis del movimiento estudiantil militante holandés, véase WERKGROEP STUDENTENOPPOSITIE (ed.), De verRaden Universiteit. De Tilburgse Studentenbeweging 1965-1975, Katholiek Hogeschool Tilburg, Tilburg, 1975. Para las memorias del líder estudiantil por excelencia de la revuelta estudiantil holandesa, véase Ton Regtien, Springtij. Herinneringen aan de jaren zestig, Wereldvenster, Houten, 1988.

24 Ibid., pp. 178-179. 
¡Sí y No! Estos ejemplos de universidades católicas convertidas en los viveros más importantes para los movimientos de contestación radical ejemplifican el hecho de que la relación entre catolicismo y movimientos sociales no fue necesariamente un vínculo de apoyo directo. El catolicismo podía también ejercer un papel negativo siendo percibido como un sistema de doctrinas e instituciones autoritarias contra las cuales uno se sentía impelido a oponerse. Y mucho más si uno se consideraba católico. Las manifestaciones más obvias de este mecanismo negativo fueron los conflictos, donde las encarnaciones concretas, por decirlo así, de la Iglesia católica estaban a cargo de hombres influyentes, pero poco amados sino más bien despreciados. También debería reseñarse que con frecuencia la particular contribución del catolicismo al surgimiento de los movimientos sociales fue una combinación de dos elementos al mismo tiempo -el refuerzo positivo y la repulsión negativa-, especialmente en el ánimo de individuos que cambiaban rápidamente de pensamiento. Una misma persona podía sentirse empujada por un profundo sentimiento de justicia social -al menos enraizado de modo parcial en las clases aprendidas durante su formación religiosa como niño- a cuestionar la autoridad y, particularmente, la autoridad de personajes católicos. Y no había mejor objetivo para esa ira justiciera que el administrador de una universidad hostil en una institución católica de alta enseñanza o, como era el caso de Lovaina, un entero episcopado alineado contra los deseos de una comunidad en plena movilización.

\section{LA DIMENSIÓN DE LA CLASE OBRERA DEL CATOLICISMO DEL 68}

No fue solo en la Universidad y en los medios católicos donde el catolicismo radical inspiró a los activistas seculares para la consecución de sus objetivos. En un gran número de países de lengua romance las organizaciones líderes de la nueva izquierda, por ejemplo, eran mucho más que simples organizaciones estudiantiles. En los países mediterráneos, la nueva izquierda tomó la forma de partidos abiertamente políticos o en la clandestinidad, como en España, donde trataron de organizarse lo mejor que pudieron, pero un modo similar. El nuevo partido político de la izquierda francesa era el Partido Socialista Unificado (PSU), que tuvo un gran papel en la radicalización estudiantil de los sesenta franceses y dejó una huella duradera en la sociedad francesa. Destacados sectores del PSU provenían directamente de medios católicos franceses de izquierda ${ }^{25}$. En España, el equi-

25 Sobre el PSU, véanse estas dos monografías: Marc HEURGON, Histoire du PSU, vol. 1: La Fondation et la guerre d'Algérie (1958-1962), La Découverte, Paris, 1994; y Bernard RAVENEL, Quand la 
valente al PSU era el Frente de Liberación Popular (FLP). Fundado, al igual que muchas realidades de la nueva izquierda europea, en 1956, en sus primeros seis años de existencia, a efectos prácticos, estaba compuesto de activistas surgidos de la floreciente izquierda católica. El FLP tuvo una influencia significativa entre los medios antifranquistas en España hasta 1969, en que el FLP, como otros muchos medios de la nueva izquierda en el mundo entero, se disolvió rápidamente ${ }^{26}$.

Tal vez, el caso más interesante de estudio de la crucial influencia de la izquierda católica en los movimientos sociales de los largos sesenta sea el veloz proceso de radicalización en los movimientos obreros de su tiempo. Porque la izquierda católica no estaba de ninguna manera limitada al medio estudiantil. De hecho, la influencia católica entre los activistas obreros era en la Europa católica, de alguna manera, más importante que en los campus universitarios. Tomemos el caso de Francia: allí era patente la presencia de estudiantes radicales católicos en los conflictos, pero también era evidente que en Francia el componente laical jugaba con ventaja. Hay muchas razones para ello, pero un factor crucial que explica esta relativa marginación de la izquierda católica estudiantil, entre la vanguardia del 1968, tiene que ver -paradójicamente- con la fuerza y el poder de los estudiantes católicos de izquierda en años anteriores. Francia se convirtió en un país altamente politizado y radicalizado en la década de los sesenta en parte debido a la experiencia de la oposición a la guerra de Argelia. Lo que fue Vietnam para los movimientos europeos y mundiales de estudiantes, fue Argelia para Francia. Es más, la organización por antonomasia de los estudiantes católicos de izquierda, la feunesse Étudiante Catholique (JEC), fue decapitada dos veces por la Jerarquía Católica mucho antes del mágico año de 1968. En 1959 y otra vez en 1965, la JEC fue despojada de sus líderes en dos oleadas de purgas contra esa organización de acción católica, la cual se había identificado con los movimientos de oposición radical contra la guerra de Argelia y sus consecuencias ${ }^{27}$.

gauche se réinventait. Le PSU, histoire d'un parti visionnaire 1960-1989, La Découverte, Paris, 2016. Dos volúmenes recientemente editados son indispensables para una completa comprensión del partido por excelencia de la nueva izquierda francesa: Tudi KERNALEGENN, François PRIGENT, Gilles RICHARD y Jacqueline SAINCLIVIER (eds), Le PSU vu d'en bas, Presses universitaires de Rennes, Rennes, 2010, y Noëlline CASTAgnEZ, Laurent JaLABERT, Marc LaZAR, Gilles MoriN y Jean-François SIRINELLI (eds), Le Parti socialiste unifié. Histoire et postérité, Presses universitaires de Rennes, Rennes, 2013.

26 La monografía pionera sobre el Frente de Liberación Popular es la de Julio Antonio GARCíA ALCALÁ, Historia del Felipe (FLP, FOC y ESBA): de Julio Cerón a la Liga Comunista Revolucionaria, Centro de Estudios Políticos y Constitucionales, Madrid, 2001.

27 El reciente trabajo, ilustrativo y estimulante, de Bernard GIROUX, La feunesse étudiante chrétienne, Cerf, Paris, 2013, quedará como la obra de referencia por muchos años. 
Pero en el campo de las clases trabajadoras no ocurrió, en Francia, una purga similar. Aquí fue la muy popular Confederación Francesa Democrática del Trabajo (CFDT), una confederación católica, más que la Confederación Comunista General del Trabajo (CGT), la que demostró mayor apertura al espíritu del 68. Y fue la Confederación Francesa Democrática del Trabajo, la que desfiló a la par con los estudiantes radicales, hecho que fue proclamado orgullosamente el 16 de mayo del 1968, al inicio de la huelga general de tres semanas de duración que sacudió los fundamentos del Estado francés: «A las libertades civiles y a los derechos dentro de las universidades deben corresponder las mismas libertades y derechos para las empresas; en esta reclamación la lucha de los estudiantes universitarios se une a la de los trabajadores que han luchado desde el origen del movimiento obrero. Debemos reemplazar la monarquía industrial y administrativa por estructuras democráticas basadas en la autogestión de los obreros» ${ }^{28}$.

La Confederación Francesa Democrática del Trabajo permanecería en el meollo del movimiento social unionista hasta inicios de los años 80. De esta manera, jugó un papel importante en la ocupación de la fábrica insignia y en el intento subsiguiente de producción bajo autogestión obrera por parte del personal en la planta relojera de LIP, cerca de Besanzón. De junio de 1973 a enero de 1974, la fábrica de relojes LIP se convirtió en la causa más popular e internacional de la izquierda radical, incluyendo a los cada vez mayores batallones radicalizados de la izquierda católica. En la misma Besanzón, la entera comunidad católica de esta pequeña población, fuertemente identificada con el catolicismo, apoyó a los trabajadores de LIP, y especialmente su arzobispo, Marc Lallier. Y uno de los líderes de esta revuelta obrera en el este de Francia era el dominico Jean Raguénès. Nacido en 1932, ordenado en 1966, ejerció desde otoño de 1967 como capellán universitario de los estudiantes de económicas y derecho de la Universidad de Paris. Su centro de operaciones era el Centro Saint-Yves en la calle Gay-Lussac,

28 El estudio clave de la transformación de la antigua federación sindical católica en la fuerza motriz del cambio radical orientado a la autogestión de la sociedad es Frank GEORGI, L'Invention de la CFDT 1957-1970, Atelier, Paris, 1995. El mismo autor proporciona un análisis excelente de los impulsos específicamente cristianos subyacentes a esta revolución, véase Frank GEORGI, De la CFTC à la CFDT. Un choix chrétien?, en: Bruno DURIEZ et al. (eds), Chrétiens et ouvriers en France, 1937-1970, Atelier, Paris, 2001, pp. 183-93. Quizás la visión general más inspiradora de la historia de la CFDT desde la década de 1940 hasta la de 1980 siga siendo la de Pierre COURSSALIÈs, La CFDT. Un passé porteur d'avenir. Pratiques syndicales et débats stratégiques depuis 1946, La Brèche, Montreuil, 1988. La cita sobre el 13 de mayo de 1968 esta sacada de Albert DETRAZ, Le Mouvement ouvrier, la CFDT et l'idée d'autogestion, en Edmond MAIRE, Alfred KRUMNOW y Albert DETRAZ, La CFDT et l'autogestion, Cerf, Paris, 1975, p. 77. 
situado en el mismo corazón de la agitación estudiantil, en la orilla izquierda de Paris. En septiembre de 1970, Jean Raguénès eligió ser uno más de la legión de entusiastas jóvenes sacerdotes obreros, tomando Besanzón como su cuartel general. Para mayo de 1971, se había convertido en un trabajador a tiempo completo en la fábrica de relojes LIP ${ }^{29}$.

Forzados por la dirección de la empresa a tomar la ofensiva, el personal de trabajadores de la fábrica LIP, con el fin de prevenir el saqueo planeado de 480 trabajadores de la línea de producción, ocuparon las instalaciones y secuestraron el stock de 25.000 relojes, y reanudaron la producción bajo su propia autoridad y supervisión, construyendo, además, una red de solidaridad a través de Francia y otros países europeos. Una de las figuras centrales y el cerebro coordinador de estas acciones no era otro que Jean Raguénès. En palabras de un antiguo trabajador de la fábrica entrevistado más de un cuarto de siglo después, Jean Raguénès «era un profeta [...] Jean había dejado su huella en la fábrica, porque había echado raíces ahí, físicamente se había abrazado a la causa de los trabajadores de LIP». Jean Raguénès tuvo un papel crucial en cada etapa de radicalización de este conflicto, el cual convirtió a la fábrica LIP en un nombre familiar en toda Europa durante algunos años, ya no como una huelga de militantes para conservar el empleo si no como «un gran paso hacia la emancipación» ${ }^{30}$. Debería añadir ahora que el más famoso activista asociado al caso de la fábrica de LIP y católico de toda la vida, era un miembro del Partido Socialista Unificado, de la Acción Católica Obrera y de la Confederación Católica Francesa Democrática del Trabajo, ¡Charles Piaget! ${ }^{31}$.

Dos ejemplos más: el movimiento de trabajadores católicos belgas demostró, a partir de 1970, ser aún más entusiasta que su contraparte socialista en adoptar la autogestión como su estandarte. Huelgas enormes y ocupaciones de fábricas encontraron más asistencia práctica y apoyo dentro de las filas de los sindicatos católicos, dominantes en la parte flamenca de Bélgica, que en la Federación Socialista. La Confederación católica de sindicatos cristianos publicó, en 1971, un

29 Existe una relativa abundancia de publicaciones sobre esta lucha laboral por excelencia de la década de 1970 en Europa occidental. Para la contribución específicamente católica, téngase en cuenta sobre todo a Jean DIVO, L'affaire LIP et les catholiques de Franche-Comté, Cabédita, Yenssur-Morges, 2003. Jean Raguénès nos ha dejado un maravilloso relato de sus experiencias como capellán de estudiantes y como cura obrero en Jean RAGUÉNÈs, De Mai 68 à LIP. Un dominicain au cœur des luttes, Karthala, Paris, 2008.

30 Citas tomadas de Divo, LIP et les catholiques, pp. 92 y 96.

31 Charles PIaget, LIP: Charles Piaget et les Lips racontent, Stock, Paris, 1973. 
manifiesto programático: «La democratización del lugar de trabajo», en el que explícitamente se abogaba por la autogestión no sólo de las fábricas sino de toda la sociedad en general ${ }^{32}$. En Italia, la federación de sindicatos católicos, la Confederación Italiana de Sindicatos de Trabajadores (CISL), mostraba más entusiasmo en su compromiso en las luchas sociales del «mayo progresista» italiano que los comunistas de la Confederación General Italiana de Trabajadores la cual, en contraste con la francesa CGT, también compitieron con los estudiantes radicales y con los obreros activistas del sessantotto italiano. La mayoritariamente católica CISL contribuyó de un modo significativo a la agitación de las relaciones de clase en las fábricas de Italia entre 1969 y $1976^{33}$.

\section{LA CONTRIBUCIÓN CATÓLICA AL NACIMIENTO DE COMISIONES OBRERAS}

A partir de 1958, y con mucha más fuerza después de 1962, los disturbios industriales en España experimentaron un serio renacimiento que empezó a socavar las bases del régimen franquista. Incluso las asociaciones obreras oficiales, sostenidas por el régimen, estaban jugando un papel crucial en la alteración del status quo. Era cada vez más frecuente la aparición de sindicatos clandestinos embrionarios que se apoyaban de manera significativa en medios católicos, buscando su apoyo y aliento ${ }^{34}$. El año 1958 también fue testigo de los primeros pasos hacia el establecimiento de las clandestinas Comisiones Obreras (CCOO), las cuales momentáneamente pasaron a ser la fuerza líder de los motines industriales anti franquistas, y rápidamente se convirtieron en una organización modelo, benefi-

32 Patrick PASTURE, Histoire et représentation d'une utopie. L'idée autogestionnaire en Belgique, en Frank GEORGI (ed.), Autogestion. La dernière utopie?, Publications de la Sorbonne, Paris, 2003, pp. 14356. Sobre los sentimientos que se filtran simultáneamente dentro de las filas de la influyente organización flamenca para adultos de la clase trabajadora católica que operan dentro del universo de Acción Católica especializada, véase Walter NAUWELAERTs, Le Kristelijke Werknemersbeweging, en Emmanuel GERARD y Paul Wynants (eds.), Histoire du Mouvement Ouvrier Chrétien en Belgique, vol. II, Leuven University Press, Leuven, 1994, pp. 501-543.

33 Un studio magistral sobre la historia del CISL es el de Guido BAGLIONI, La lunga marcia della CISL.1950-2010, Il Mulino, Bologna, 2011. Una sencilla mirada a la dinámica sobre del activismo católico de izquierda dentro del CISL y sus consecuencias para el activismo sindical en los años sesenta, en mi obra Spirit of Vatican II, pp. 215-227.

34 Es importante señalar que el catolicismo progresista español de finales de los años 1950 y principios y mediados de los 60 , precedió al Concilio Vaticano II y debe considerarse como un producto autónomo de las circunstancias extraordinarias y dramáticas de la sociedad española que entonces vivía bajo un régimen dictatorial. 
ciándose con frecuencia de la cooperación práctica de algunos de los sindicatos clandestinos mencionados antes que en sus orígenes habían tenido una inspiración en su mayoría católica ${ }^{35}$.

Hoy las CCOO son consideradas históricamente como una organización muy cercana al Partido Comunista Español (PCE), sobre todo desde que empezaron a operar, en la clandestinidad, contra el franquismo. Sin lugar a dudas, los trabajadores comunistas tuvieron un papel fundamental como líderes de las CCOO desde sus inicios, y en la segunda mitad de los sesenta consolidaron su control sobre la organización. Sin embargo, en los primeros pasos de las Comisiones Obreras la contribución católica en la concepción, nacimiento, crecimiento inicial y desarrollo de las Comisiones Obreras fue crucial. Una ojeada a los momentos en que se fundaron estos comités radicales -los cuales, durante algún tiempo, debido a las presiones del control dictatorial franquista, estuvieron forzados a permanecer relativamente aislados y funcionando de una manera autónoma o, como mucho, en organizaciones regionales-, dice mucho respecto al papel imprescindible de los trabajadores católicos.

Durante la primera mitad del siglo $\mathrm{XX}$, los activistas asturianos y sus organizaciones tuvieron un papel fundamental en el movimiento obrero español, y eso confirma la tesis de que algunos de los primeros brotes del activismo dentro de CCOO bajo el régimen franquista podrían rastrearse en esta combativa provincia. Algunos intentos de crear comisiones de obreros tuvieron lugar a partir de 1956, y las dos subculturas políticas que estuvieron a la cabeza de esos movimientos fueron el PCE y la Hermandad Obrera de Acción Católica $(\mathrm{HOAC})^{36}$, la sección española del Movimiento Mundial de los Trabajadores Cristianos. Este último reuniendo todas las organizaciones que representaban a las clases obreras de la acción católica especializada para adultos. El activista de la HOAC, Manuel Hevia Carriles, fue detenido por su discurso combativo con ocasión de una campaña apostólica en Gijón en 1952, al igual que otro activista, José Borbolla, en 1954 en Avilés. La crucial contribución de la HOAC al crecimiento de las CCOO en su territorio natal de Asturias fue la consecuencia natural de su actitud y orientación en esos años previos $^{37}$.

35 Aún ahora la obra más útil sobre la historia de las CCOO es la de David RuIZ (ed.), Historia de Comisiones Obreras (1958-1988), Siglo XXI, Madrid, 1993.

36 El historiador más destacado de la HOAC es Basilisa López García. Téngase en cuenta, sobre todo, su Aproximación a la bistoria de la HOAC, 1946-1981, HOAC, Madrid, 1995.

37 Rubén VEGa GARCÍA, Cristianos en el movimiento obrero asturiano durante el franquismo. Un apunte, en XX Siglos, 5/22 (1994), pp. 4-5. 
La primera comisión de obreros llamada a perdurar en el tiempo y a inspirar a otras parecidas -y ahora es vista, por lo general, como el clásico ejemplo de comisión de trabajadores que opera con éxito en condiciones adversas-, fue la Comisión obrera del complejo minero de La Camocha. Aquí -en la vecindad de las comunidades mineras- los activistas de la HOAC jugaron un papel imprescindible como paradigma y símbolo. De hecho, en La Camocha, el párroco local fue uno de los miembros de coordinación de dicha comisión desde sus inicios ${ }^{38}$. La ola de huelgas de 1962 se concentró en Asturias y en las vecinas provincias de Vizcaya y Guipúzcoa, donde el gobierno de Madrid tomó medidas drásticas proclamando el estado de emergencia. Los valles mineros al sur de la capital de Asturias, en Oviedo, quedaron encuadrados en el centro de ese conflicto. El 24 de abril de 1962 todas las minas del área cerraron en una acción coordinada. Ese mismo día, delegados de todos los pozos mineros afectados se reunieron para un encuentro en el que eligieron otra novedad para la España clandestina: un comité de huelga. El encuentro fue moderado por uno de los líderes activistas de la HOAC, Manuel Morillo, con el organizador central de la HOAC nacional, Jacinto Martín, asesorando el proceso entre bastidores ${ }^{39}$. Jacinto Martín, al igual que muchos otros líderes claves de las hermandades obreras había sido profundamente influido por la teoría y práctica anarcosindicalista en su juventud, introduciendo muchos de sus principios en la teoría social católica y en la práctica dentro de la HOAC en la España franquista de 1950-1960. Manuel Morillo había sido miembro del Partido Comunista Español.

Los trabajadores católicos lucharon codo con codo con los miembros del Partido Comunista Español en los conflictos mineros e industriales en el País Vasco. En Vizcaya, la huelga de 1962 dio rápidamente como resultado el arresto de 52 activistas. Las comisiones locales de obreros eligieron cinco portavoces para que iniciaran las negociaciones con las autoridades a fin de conseguir su liberación. La mayoría de estos líderes eran miembros de la HOAC. Este comité coordinador de emergencias se transformó en el comité que lideraría a las CCOO de Vizcaya, jla primera sección de las Comisiones Obreras de rango provincial en toda España! Y de nuevo, los activistas de la HOAC (y de las JOC) continuaban ejerciendo importantes funciones ${ }^{40}$. Otro de los lugares donde los activistas

38 Javier DomíngueZ, Las Vanguardias Obreras en la lucha por la democracia, en XX Siglos, 4/16 (1993), p. 70.

39 LÓpez García, Aproximación..., op. cit., p. 144.

40 Pedro Ibarra GüEll y Chelo García MARroquín, De la primavera de 1956 a Lejona 1978. Comisiones Obreras de Euskadi, en David RUIZ (ed.), Historia de Comisiones..., op. cit., p. 116. 
católicos -y en particular los de la HOAC- tuvieron un papel fundamental en el lanzamiento de las CCOO fue en Burgos ${ }^{41}$; también en la provincia vasca de Álava, donde las $\mathrm{CCOO}$, por razones prácticas, surgieron dentro de las asociaciones católicas radicalizadas que incluían a miembros de la HOAC, pero también a activistas de la red radical jesuitica, Vanguardias obreras ${ }^{42}$; Andalucía ${ }^{43}$; y muchas otras áreas industriales y mineras importantes a lo largo y ancho de España. El catolicismo progresista tuvo un papel sobresaliente en la oposición obrera anti franquista de mediados de los cincuenta a mediados de los sesenta, al igual que había pasado en otras partes de la Europa católica, aunque solamente de los años sesenta para adelante.

\section{LA RADICALIZACIÓN DEL SACERDOCIO}

Las agitadas comunidades obreras de los largos sesenta, especialmente sus militantes católicos, también revitalizaron el fenómeno de los sacerdotes obreros, un movimiento social sui generis, que había generado un interés internacional en la segunda mitad de los años 40 y en la primera de los 50. Diseñada para revertir la marea de la descristianización de la clase trabajadora al mostrar el compromiso con los valores de la clase obrera por medio de sacerdotes que cambiaban su sotana por el mono de trabajo, el pequeño número de sacerdotes obreros que trabajaron en la inmediata postguerra, al final, más que lograr la atracción hacia la fe católica terminó por adoptar el estilo de vida y la visión política de sus camaradas laicos $^{44}$. Hacía 1954 en Francia (1955 para Bélgica) la jerarquía eclesiástica, que apenas diez años antes había animado esta experiencia, denegó a los sacerdotes (y a los miembros de las órdenes religiosas) la autorización para comprometerse

41 Enrique BerZal de la Rosa, Sotanas rebeldes. Contribución cristiana a la transición democrática, Diputación de Valladolid, Valladolid, 2007, pp. 82-83.

42 GǗLll y MarRoQuín, De la primavera..., op. cit., p. 118.

43 Para el contexto andaluz, con particularidades importantes, véase José HuRTADO SÁNCHEZ, Sevilla: Obreros cristianos en la lucha por la democracia, en José María CASTELls, José HuRTADO y Josep Maria MARgEnat (eds.), De la dictadura a la democracia. La Acción de los cristianos en España (1939-1975), Desclée de Brower, Bilbao, 2005, pp. 366-367; y Carmen R. GARCÍA RuIZ y Alberto CARrillo Linares, Cobertura de la Iglesia a la oposición. La colaboración con CC.OO. Los casos de Málaga y Sevilla, en ibid., pp. 411-421.

44 De la relativa abundancia de publicaciones sobre lo que yo llamo la primera ola de sacerdotes obreros, deseo resaltar la de Émile POULAT, Naissance des prêtres-ouvriers, Casterman, Paris, 1965; y la de Oscar L. ARnal, Priests in Working-Class Blue. The History of the Worker-Priests (19431954), Paulist Press, New York, 1986. 
a tiempo total en trabajos asalariados de carácter industrial y, de esta manera, fue cerrado, prematuramente, un capítulo prometedor en el apostolado de la clase obrera de la Iglesia católica ${ }^{45}$.

El 23 de octubre de 1965, en las postrimerías del Vaticano II, una asamblea plenaria extraordinaria de obispos franceses -atrapada en la vorágine de la efervescente atmósfera surgida en el desarrollo del Vaticano II-, aprobó por unanimidad la reanudación de la experiencia de los curas obreros. Así, el movimiento que había sobrevivido en varias formas hibridas por espacio de diez años, brotó de nuevo. El primer grupo de curas obreros estaba limitado, en términos geográficos, a Francia (allí precisamente un centenar de curas obreros había ejercido su actividad antes de la cancelación de 1954) y a Bélgica. Mientras que el número más alto del primer grupo de curas obreros en Bélgica nunca fue probablemente superior a ocho, el segundo grupo superó con creces esa cifra. En Francia, el punto más alto se alcanzó hacia finales de los 70, cuando más de 1000 sacerdotes se habían puesto el mono de trabajo; en Bélgica esto ocurrió en 1974, cuando 51 sacerdotes se comprometieron a la vez en un trabajo a tiempo completo ${ }^{46}$. Más llamativo, ciertamente al compararlo con el primer y segundo grupo de sacerdotes obreros (después de 1965), fue que el movimiento, que había estado estrictamente limitado a Francia y a Bélgica en la primera década después de la segunda Guerra Mundial, ahora comenzaba a extenderse de modo muy rápido a todos los países católicos de la Europa occidental ${ }^{47}$.

Pero una innovación aún más asombrosa dentro del mundo sacerdotal católico, después del Vaticano II, fue la repentina aparición, aparentemente de la nada, de asociaciones de sacerdotes radicales durante el año 1968 y en los si-

45 Sobre la Abwicklung de las experiencias de los curas obreros de mitad de los 50, véase sobre todo François LEPRIEUR, Quand Rome condamne. Dominicains et prêtres-ouvriers, Plon, Paris, 1989.

46 Sobre la reautorización de la experiencia de los curas obreros el 23 de octubre de 1965, véase, por ejemplo, Pierre PIERRARD, L'Église et les ouvriers en France. 1940-1990, Hachette, Paris, 1991, pp. 348-349. Para el total de sacerdotes obreros belgas, véase el cuadro incluido en las páginas sin numerar entre las páginas 75 y 76 en Dominique DE GREEF, Les prêtres-ouvriers en Belgique, Mémoire de license, 1985, Faculté de Théologie, Université de Louvain.

47 No existe un estudio general sobre la segunda ola del fenómeno de los sacerdotes obreros. Para casos nacionales específicos, hay una literatura lentamente emergente; en Italia, se puede ver, por ejemplo, Marta MARGOTTI, Lavoro manual e spiritualità. L'itinerario dei preti operai, Studium, Rome, 2001; y también Giuseppina VITALE, L'anima in fabbrica. Storia, percorsi e riflessioni dei preti operai emiliani e lombardi (1950-1980), Studium, Rome, 2017. Una primera aproximación a la experiencia española de los curas obreros en José CENTENO GARCÍA, Luis DÍEZ MAESTRO y Julio PÉrez Pinillos (eds.), Curas obreros. Cuarenta y cinco años de testimonio. 1963-2008, Herder, Barcelona, 2009, y notablemente Julio PÉREZ PINILlos, Los curas obreros en España, Nueva Utopía, Madrid, 2004. 
guientes seis años. No había existido una organización o movimiento equivalente antes, incluyendo la etapa después de la Segunda Guerra Mundial. Ahora, de repente, algunos párrocos y miembros de orden de religiosas comenzaron a actuar por su cuenta, y sus planteamientos se radicalizaron a medida que se desarrollaba la protesta. El movimiento ganó terreno primero en los Países Bajos que, como se ha mencionado antes, en los años 60 , se había convertido en un laboratorio de experiencias innovadoras dentro de las comunidades católicas, en gran medida debido al hecho de que todo el episcopado holandés era el que apoyaba las medidas de reforma radicales reclamadas por una parte significativa de sus sacerdotes ${ }^{48}$.

Si se puede hablar de un problema general que agitaba la vida de los sacerdotes en cada país europeo, ese era la cuestión del celibato ${ }^{49}$. Tras el Vaticano II, muchos observadores esperaban un pronunciamiento papal que liberalizara la cuestión. Sin embargo, como pasaban meses y años sin que hubiera movimiento al respecto por parte de Roma, algunos sacerdotes decidieron afrontar el asunto por su cuenta. Los sacerdotes que se casaban y buscaban una nueva profesión, renunciando a su estatuto de sacerdote, eran un fenómeno conocido a lo largo de la historia, así como los conflictos de los sacerdotes que vivían con una amante, aunque este último caso se llevara habitualmente de modo encubierto. A finales de los años sesenta, en la atmósfera general de experimentación y de afirmación de nuevos derechos, el número de sacerdotes que querían evitar la hipocresía y el recurso al continuo encubrimiento creció exponencialmente. Uno de los primeros que desafió frontalmente la doctrina establecida en este punto fue Jos Vrijburg, capellán de estudiantes en la célebre Amsterdamse Studentenecclesia, la parroquia estudiantil de la Universidad de Ámsterdam. En noviembre de 1968, Jos Vrijburg anunció públicamente su intención de casarse sin renunciar a la sotana. Sus superiores de la liberal jerarquía holandesa, le manifestaron su comprensión, pero también de modo inequívoco le comunicaron que no podían consentir esa decisión unilateral. Los planes matrimoniales de Jos Vrijburg se convirtieron en el tema de conversación del pueblo y el centro de animadas discusiones en toda Holanda ${ }^{50}$.

48 Todavía la explicación más convincente en cualquier idioma para el inesperado papel de vanguardia del catolicismo holandés es John A. COLEMAN, The Evolution of Dutch Catholicism, 1958-1974, University of California Press, Berkeley, 1978.

49 No existe ningún estudio serio acerca de la controvertida discusión sobre el celibato de los clérigos a finales de los 60. Sobre un asunto que guarda relación y que atrajo la atención de un público amplio, el surguimiento de la contracepción. Véase, por ejemplo, Martine SĖVEGRAND, L'affaire Humanae Vitae, Karthala, Paris, 2008.

50 Una breve aproximación a Jos Vrijburg, completada con fotos de su boda el 27 de junio de 1969, puede leerse en http://www.huubmous.nl/2009/02/28/prima-della-rivoluzione/ 
Dos jóvenes sacerdotes de la diócesis de Haarlem (Holanda), Joep ter Linden y Pieter Jan Blankendaal, en la víspera de su partida para las misiones en Brasil, fueron a visitar a un nutrido número de amigos y colegas para despedirse, y les sorprendió como el caso Vrijburg o, en concreto, el tema del celibato, salía a colación en cada una de las conversaciones con sus colegas. Durante sus reuniones [de Joep ter Linden y Pieter Jan Blankendaal] con un joven capellán en Beverwijk, Jan Ruijter, surgió la idea de organizar un encuentro con otros sacerdotes para discutir el tema en un contexto más amplio. Cada uno de los tres sacerdotes presentes en la casa de Ruijter llamó a otros cinco compañeros, sugiriéndoles que a su vez llamaran a otros cinco sacerdotes y así sucesivamente, con la vista puesta en una reunión para dentro de pocos días ${ }^{51}$.

El 16 de diciembre de 1966, 73 sacerdotes se congregaron en un amplio salón del Hotel Americano de Ámsterdam para discutir sobre el tema del celibato, sobre la declaración de intenciones de Jos Vrijburg, y lo que ellos podían hacer acerca de esta situación. El reducido grupo decidió redactar una carta dirigida a los obispos holandeses, pidiéndoles tomar una decisión unilateral que permitiese seguir contando con sacerdotes casados en las iglesias, sin la necesidad de esperar la aprobación de Roma. Los nombres de los firmantes aparecían en negrita al final de la carta ${ }^{52}$. La prensa y la televisión habían sido convocados a la reunión del Hotel Americano, para asegurarse la resonancia pública de la reunión. A los pocos días, un aluvión de cartas escritas tanto por sacerdotes seculares como religiosos de toda Holanda y algunas de ellas bajo la forma de carta colectiva representando hasta a doce sacerdotes, colapsaban el correo del grupo del Hotel Americano, manifestando su adhesión a la propuesta.

Un segundo encuentro tuvo lugar el 14 de febrero de 1969 al que asistieron el doble de sacerdotes. Se formó un Comité Coordinador que se sentó a redactar una carta dirigida a todos los sacerdotes católicos holandeses y en la cual se trataban otros asuntos más allá de la cuestión del celibato. La Iglesia, los laicos, sacerdotes, obispos y el papa eran emplazados a modernizar su perspectiva, su estructura interna y su orientación ${ }^{53}$. El Comité Coordinador estaba formado por

51 Richard AuwERDA, Vier jaren geschiedenis, en Conto, 6/11 (noviembre 1972), p. 4.

52 Septuagintgroep (ed.), Septuagint van Chur naar Rome. Dossier van de solidaire priestergroepen, Katholiek Archief, Amersfoort, 1969, pp. $11+22$, con el texto de la carta reproducido en las pp. 10-11. Una copia de la carta original manuscrita con la lista de nombres al final, puede ser consultada en el KATHOLIEKE DOCUMENTATIE CENTRUM (KDC), Fonds Septuagint (LXX), f. 107. La colección de cartas expresando su apoyo a esta iniciativa se encuentran en el KDC, LXX, f. 15 .

53 Inleiding van 7. Ruyter, pp. 23-24. El texto de la carta enviada a todos los sacerdotes holandeses está reproducido en SEPTUAGINTGROEP (ed.), Van Chur naar Rome, pp. 12-19. 
20-30 sacerdotes que se reunían con relativa frecuencia en Utrecht, ostentando, de facto, el liderazgo. Un informe financiero de septiembre de 1969 contabiliza en 605 personas el número de miembros de este grupo, incluyendo un número no despreciable de personal de órdenes religiosas, entre los cuales había sesenta y cuatro monjas ${ }^{54}$.

La Septuaginta, nombre con el que era conocido este círculo de sacerdote rebeldes, rápidamente llegó a ser un actor importante en la vida pública holandesa, beneficiándose de la atmósfera liberal entonces prevalente en la Iglesia católica holandesa. A partir de julio de 1969, activistas laicos comenzaron a unirse a la Septuaginta como miembros de pleno derecho, aunque permanecieron, la mayor parte de ellos, en un segundo plano. Para octubre de 1969, según una fuente, 1.300 sacerdotes católicos holandeses habían expresado su solidaridad con las metas de la organización. En mayo de 1970, un grupo de 60 ministros críticos pertenecientes a una de las mayores denominaciones del protestantismo holandés, la Hervormde Kerk, se unió a la Septuaginta. Dos meses más tarde, alrededor de cien jesuitas, el grupo Helvoirt, igualmente se unió a la Septuaginta. El viento soplaba claramente a favor del grupo insurgente que desafiaba a las autoridades ${ }^{55}$. En el punto de máxima extensión de la Septuaginta es probable que se llegara a los 2000 miembros. Una proporción significativa de este número -aunque nunca más de la mitad- eran miembros laicos. Sin embargo, al menos alrededor de 1000 sacerdotes holandeses estaban directamente involucrados en la dinámica de este grupo. Como los Países Bajos contaban en aquel tiempo con unos $4000 \mathrm{sa}-$ cerdotes seculares, esto suponía que la Septuaginta era, con mucho, el grupo más importante de Europa en términos de control sobre una proporción significativa del clero nacional ${ }^{56}$.

54 Septuagint-Kasoverzicht-18 September 1969 - KDC, LXX, f. 200.

55 Gran parte de la información en este párrafo proviene de una sinopsis de diez páginas sin fecha de la historia de la Septuaginta, escrita en 1975 o poco después: Septuagint - KDC, LXX, f. 1. La cifra de 1.300 sacerdotes expresando su solidaridad es mencionada por Herman VERBEEK, fournaal van 14 dagen Rome, en SEPTUAGINTGROEP (ed.), Van Rome naar Utrecht, Katholiek Archief, Amersfoort, n.d., p. 34. La inscripción colectiva del Helvoirtgroep está documentada en SEPTUAGINTGROEP (ed.), Van Utrecht naar huis...?, Archief van de kerken, Amersfoort, 1970, pp. 357. Las cifras concretas de los protestantes miembros de la Septuaginta están mencionadas en un informe sin firma, Bericht zur Lage der Nation - Nation: Niederlande, Beverwijk, mei 1970 - KDC, LXX, f. 1.

56 La estimación de «aproximadamente mil» sacerdotes entre el número total de la Septuaginta se basa en la opinión informada de su antiguo rector espiritual, Jan Ruijter, expresada en una conversación con el autor el 24 de octubre de 2013. El número de sacerdotes seculares holandeses está tomado de Walter GODDIJn, Jan JaCOBS y Gérard VAN TILlo, Tot vrijheid geroepen. Katholie- 


\section{DE ÁMSTERDAM a CHUR}

Dada la inusual y firme implantación de sacerdotes radicales holandeses dentro de las estructuras institucionales de una iglesia orientada a la reforma, se hizo patente que la Septuaginta tendría un papel crucial en la coordinación de esfuerzos para fabricar una red internacional de sacerdotes con ideas afines. La segunda reunión de la Septuaginta, en el Hotel Americano del 14 de febrero de 1969, de hecho, contó con representantes de organizaciones hermanas alemanas y francesas entre los cerca de 150 asistentes. La carta a todos los sacerdotes católicos holandeses, a la que nos hemos referido anteriormente, emanada de esta asamblea, terminaba con un plan de acción que se enfocaba principalmente a la consecución de una asamblea internacional de sacerdotes críticos, que se celebraría en Chur (Suiza), en principio, a mediados de julio de 1969. La ocasión fue una conferencia preparatoria de obispos europeos en el pueblo más antiguo de Suiza, convocada con el fin de organizarse para el inminente sínodo mundial extraordinario de obispos que se celebraría en Roma en octubre de 1969. «Nuestro grupo de acción, en colaboración con sacerdotes de otros países, intenta enviar representantes a Chur con la finalidad de seguir de cerca la Conferencia de Obispos y asegurarse de que, tanto en las publicaciones como en la documentación, pueda tener cabida una contribución 'extraparlamentaria' $»^{57}$.

De esta manera surgió, de forma casi espontánea, un producto claro de mezcla y fusión del espíritu del 68 con el espíritu del Vaticano II. Chur reunió, por primera vez en la historia, sacerdotes disidentes de varios puntos de Europa en un esfuerzo por presionar a la jerarquía de la Iglesia, en el proceso de conocerse cada uno y darse cuenta de que las batallas individuales que se daban en sus respectivos países formaban parte de algo más grande, de una campaña continental. Los casi cien sacerdotes radicales que habían llegado sin grandes expectativas a Chur, regresaron a su casa desilusionados -dado que los obispos europeos reunidos les habían dado la espalda- pero, sin embargo, se realimentaron debido a las nuevas

ken in Nederland 1946-2000, Ten Have, Baarn, 1999, p. 504. Es una aproximación basada en una interpretación autorizada de los gráficos relativamente detallados. Agradezco a Lodewijk Winkeler por esta referencia, junto con su interpretación de los gráficos, según la cual «en 1970 había alrededor de 3833 sacerdotes seculares» en los Países Bajos; véase el mail de Lodewijk Winkeler a Gerd-Rainer Horn, 28 de octubre de 2013.

57 Cita tomada de un escrito tipográfico de la carta, fechada en «marzo de 1969», «Aktiegroup Priesters 'Septuagint», «Aan alle priesters in Nederland»-KDC, LXX, f. 1. 
conexiones que habían establecido en las largas discusiones nocturnas. Durante varios años, este movimiento, muy pronto denominado la Asamblea Europea de Sacerdotes y después el Congreso Internacional de Solidaridad Cristiana, animaba a grupos de sacerdotes y a la opinión pública con dos reuniones internacionales (Roma en octubre de 1969 y Ámsterdam en septiembre/octubre de 1969) que impulsaron su autoestima antes de desaparecer definitivamente hacía mediados de los años $70^{58}$.

\section{CONCLUSIÓN}

El rápido ascenso y caída de esta organización de la Solidaridad Cristiana era sintomática de este fugaz florecimiento de la segunda ola de catolicismo de izquierdas. Después de atraer la atención rápidamente de los medios de comunicación y de un público más amplio, las manifestaciones concretas del espíritu de Vaticano II se debilitaron significativamente en el curso de los años 70. En la segunda mitad de esta década eran, a lo sumo, una sombra de lo que habían sido antes, ¿cómo puede uno entender este fenómeno? y ¿cuáles fueron las mecánicas de su interacción con el espíritu proverbial del 68?

Antes del año 1968, el espíritu del Vaticano II había proporcionado importantes y cruciales estímulos al espíritu emergente del 68. Dentro de los movimientos de estudiantes y organizaciones de clases trabajadoras afines, desde mediados de los 60 en adelante, el activismo católico radical había representado durante esos años trascendentales, un papel importante y extraordinario con manifestaciones adelantadas a su tiempo. A pesar de los espectaculares eventos y altercados públicos del año 1968 la dinámica pronto se invirtió. Después de 1968, la invocación del espíritu del 68 fue lo que ayudó en la promoción y radicalización del espíritu del Vaticano II. Una vez que el activismo secular comenzó a multiplicarse, pronto superó en importancia a las contribuciones hechas por parte del movimiento cultural de los largos sesentas en su vertiente específicamente

58 Existen las siguientes monografías sobre los miembros franceses y alemanes occidentales del Congreso Internacional de Solidaridad Cristiana, Edgar UTSCH y Carl-Peter KLUSMAN (eds.), Dem Konzil verpflichtet-verantwortlich in Kirche und Welt. Priester-und Solidaritätsgruppen in Deutschland (AGP) 1969-2010: eine Bilanz nach 40 Fahren, LIT, Münster, 2010; y Sylvaine GUINLE-LORINET, Libérer le prêtre de l'état clerical. Échanges et dialogue (1968-1975), L'Harmattan, Paris, 2008. Para la reconstrucción del auge y caída del Congreso Internacional de Solidaridad Cristiana, véase mi Spirit of Vatican II, pp. 86-109. 
católica. Además, gran parte de la jerarquía eclesiástica, incluyendo a Pablo VI, empezaron a aplicar los frenos al catolicismo radical a raíz de las controvertidas actuaciones llevadas a cabo por parte de la politizada izquierda católica, poniendo a la defensiva a los católicos progresistas y, desde mediados de los años 70 en adelante, la segunda ola del catolicismo de izquierdas comenzó a disminuir y a desintegrarse paulatinamente. Para finales de los 70 y principios de los 80, los proyectos utópicos de la izquierda católica se habían convertido en una historia lejana, desvaneciéndose de la memoria tan rápidamente como se habían elevado en la luna de miel de 1965 a 1968. 